\title{
Investigating the influence of water injection on the emissions of a diesel engine
}

\author{
M. Kettner ${ }^{*}$, S. Dechent ${ }^{1}$, M. Hofmann'1, E. Huber'1, H. Arruga1, R. Mamat ${ }^{2}$ \\ and G. Najafi ${ }^{3}$ \\ ${ }^{1}$ Karlsruhe University of Applied Sciences (HsKA) \\ *Email: maurice.kettner@hs-karlsruhe.de \\ Phone: +49 721925 1845; Fax: +49 7219251915 \\ 76133 Karlsruhe, Germany \\ ${ }^{2}$ Faculty of Mechanical Engineering, Universiti Malaysia Pahang, \\ 26600 Pekan, Pahang, Malaysia \\ ${ }^{3}$ Tarbiat Modares University, Tehran, Iran
}

\begin{abstract}
There are many methods to decrease the nitrogen oxide emissions of a diesel engine. One promising measure is water injection into the engine's intake manifold. As emission limits become more and more stringent, the diesel engine $\mathrm{NO}_{\mathrm{x}}$-particulate trade-off is a challenge for engine developers. To overcome this challenge, a single-point water injection system has been developed to investigate the influence of different amounts of injected water on the behaviour of a 4-cylinder diesel engine. The amount of injected water was varied from 0 to $100 \%$ water-to-fuel ratio in part-load operation (BMEP $=2$, 3.5 and 5 bar). The influence on the intake air cooling effect, exhaust emissions, combustion and engine parameters was evaluated. The combustion temperature and the $\mathrm{NO}_{\mathrm{x}}$ emissions decreased drastically $\left(63 \% \mathrm{NO}_{\mathrm{x}}\right.$ decrease for a BMEP of 5 bar and a waterto-fuel ratio of $100 \%)$. This benefit had the drawback of an increase of the particle matter emission at high water-to-fuel ratio. The combustion process and performance parameters regarding efficiency, torque and fuel consumption were marginally influenced by the water injection. This work has achieved a major reduction of $\mathrm{NO}_{\mathrm{x}}$ raw emissions of a diesel engine. Further research lines could include research on water injection at high load operation points in the engine map.
\end{abstract}

Keywords: Diesel engine; water injection; $\mathrm{NO}_{\mathrm{x}}$ emission.

\section{INTRODUCTION}

Emissions of diesel engines are typically characterised by a $\mathrm{NO}_{\mathrm{x}}$-particulate trade-off, as shown in Figure 1. By variation of the engine operation parameters such as the injection timing, $\mathrm{NO}_{\mathrm{x}}$ emissions can be decreased but particulate emissions increase and vice versa. Lowering both emission components does not seem to be feasible with standard operation parameters. Therefore, some measures like exhaust gas recirculation (EGR), reduced compression ratio or intercooling allow a slight lowering of both emission components. Although all of the mentioned in-cylinder measures reduce the engine's raw emissions, the additional use of exhaust gas after-treatment systems is necessary in order to fulfil stringent emission limitations. In Europe, almost all diesel vehicles use particulate traps. Consequently, the targets of $\mathrm{NO}_{\mathrm{x}}$ emission can be reached by applying simple strategies like late injection timing, which involves a high raw particulate formation. Unfortunately, this comes with an increase in fuel consumption due to the delayed combustion phasing. 
Water injection (WI) seems to be an appropriate method to reduce $\mathrm{NO}_{\mathrm{x}}$ emission with only small drawbacks in terms of particulate emission, fuel economy and engine performance. Furthermore, electronically controlled water injection systems allow a flexible water rate depending on the engine operation point [1].

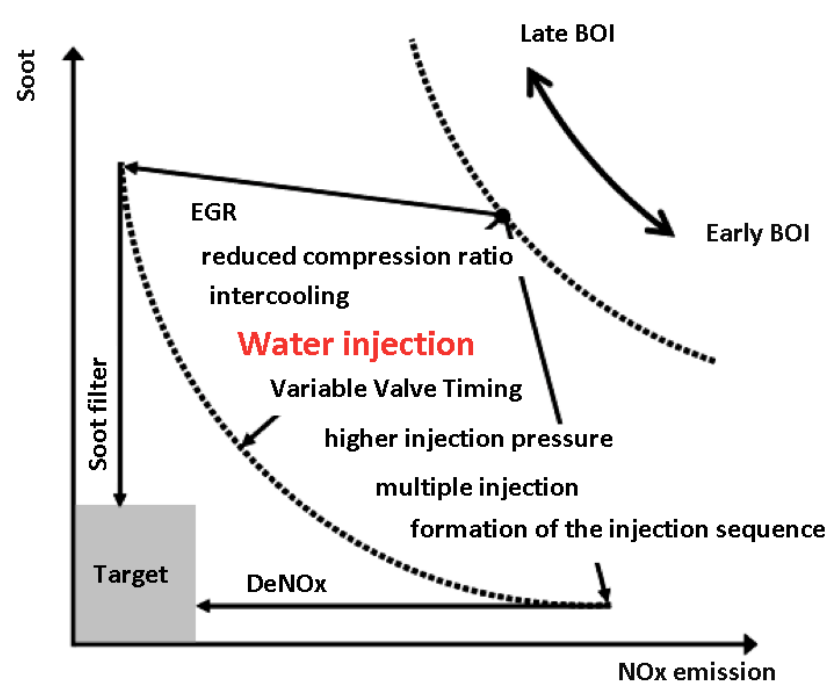

Figure 1. $\mathrm{NO}_{\mathrm{x}}$-particulate trade-off and different measures for emission reduction [1].

The origin of the idea of using water to improve the engine process in general dates a long way back. Engineers have had considerable success with their special applications, some more than others, but none has yet shown a marvellous breakthrough towards mass production. The following time-line provides an overview of different water injection applications over the last 100 years. In 1910, Otto Vollnhals carried out the first experiments with a mixture of air, atomised fuel and water in a petroleum-fuelled hotbulb engine [2]. In 1940, a mixture of water and methanol was used in an air combat fighter Messerschmitt Bf109G-10. This system increased the engine power from 1700 to 2400 HP [3]. In 1983, Renault was the first Formula 1 engine builder to use water injection in race engines to cool the compressed air so as to prevent knocking of the engine [4]. In 1988, Saab started mass production of the first turbocharged car with an optionally available water injection system [5]. In 1992, Ford introduced a water injection system in the World Rally Championship (WRC); all other teams followed by 1997 (except for Mitsubishi) [6]. In 2007, the German engine tuning company MTM presented a water injection system to move the detonation limit in Otto engines. This system was developed together with Ingolstadt UAS [7]. In 2014, the German company Exomission launched a Fuel Water Emulsion (FWE) system for marine diesel propulsion [8]. In 2015, BMW released its M4 safety car with an innovative water injection system at the Qatar Grand Prix [9]. Different methods to add the water to the engine have been investigated by numerous researchers in the last decades.

\section{Humid Air Method}

The general idea is to add water vapour to the intake air. Depending on the application purpose, moistening can be provided in different ways. For stationary engines, water vapour can be added to the intake air to increase its relative humidity. Another method 
consists of using a humidifier for the intake air with a water circulation. The air can be saturated to the maximum and excess water is absorbed and recirculated. Riom et al. [10] applied the Humid Air Method to a ship engine, adding water to the air downstream of the compressor of the turbocharger using a "humidification tank".

\section{Water Injection into the Intake Manifold}

Various techniques to inject liquid water into the intake manifold are presented in the literature, for example: single point injection, injection upstream of the compressor, injection downstream of the compressor, or multipoint WI in the intake pipes near the inlet valves. All locations have advantages and drawbacks but the thermodynamic mechanisms are very similar. Samec et al. [11] carried out an experimental investigation of water injection by two methods: using an injector for intake manifold multipoint water injection downstream of the compressor and using a spray system which continuously adds water into the turbocharger inlet of a diesel engine. Kegl et al. [12] compared four different water injection methods for a truck diesel engine: fuel/water emulsion in the combustion chamber, multipoint water injection in the intake manifold and single-point water injection upstream and downstream of the turbocharger. Odaka et al. [13] combined EGR and intake manifold water injection in a heavy-duty diesel engine. Tauzia et al. [14] used a modified gasoline injector and an air compressor to mix the water with the air and to obtain a fine mist that was injected before the inlet manifold of a high-speed commonrail automotive diesel engine.

\section{Direct Water Injection}

In research and development projects found in the literature, different approaches were used to put a direct water injection system into practice. The water can be injected separately from the diesel fuel or in a combined injector for fuel and water. This injector has a fuel and water supply line. The injection is characterised by stratification between the water and diesel. The adjustment of the water-to-fuel ratio is done by a solenoid valve in the water line. Takasaki [15] performed experiments using this type of injector.

\section{Fuel-Water Emulsion}

Numerous research projects have been accomplished with fuel-water emulsion, leading to significant reductions in $\mathrm{NO}_{\mathrm{x}}$ and soot emissions. There are different ways to implement such a system. The first way is with two pumps and one injector. In this system, the existing fuel supply of the engine is modified. A T-piece close to or in the injector is installed. With this component, water can be added to the fuel and mixing occurs in the injector. The second way is with one pump and one injector. The whole injection system, including the fuel supply, is used to work with "premixed" FWE. Subramanian [16] investigated the effects of water-diesel emulsion and water injection into the intake manifold on the performance, combustion and emission characteristics of a DI diesel engine under similar operating conditions.

\section{Hybrid Water Injection Systems}

BMW [17] has developed a system that combines and uses at the same time water injection into the intake plenum with high-pressure direct injection of a mixture of gasoline and water. As a water source, the released water condensate from the air conditioning system is stored in a tank and used for both water injection systems. The water injection into the plenum is varied from 0 to $5 \%$ water-to-fuel ratio. This value is limited by the maximum amount of water that the intake air can absorb. With the direct 
injection, the water contained in the water-gasoline mixture is varied from 0 to $30 \%$. With this system, a significant improvement in engine power with low emission and fuel consumption is achieved simultaneously.

In this work, a single-point water injection in the intake manifold downstream of the intercooler of an Isuzu diesel common rail engine was carried out. The injector used is a Mitsubishi GDI swirl-type injector which was operated with 5 bar water pressure. Different orientations and locations of the injector with respect to the air flow direction (unidirectional, sideways and reverse to air flow) as well as various water-tofuel ratios (from 0 to $100 \%$ ) were tested. The influence on engine operation and performance was examined. Several parameters and variables to characterise the behaviour of the engine were investigated, such as: the intake air temperature reduction due to water injection, the transient behaviour of the air flow temperature after the start of water injection, the variation of the $\mathrm{NO}_{\mathrm{x}}$ and particulate emissions of the engine, the change in engine performance parameters (IMEP, brake efficiency and specific fuel consumption) and the effect of water injection on combustion parameters such as the cumulative heat release rate and ignition delay.

\section{THEORETICAL BACKGROUND}

\section{Theory of Water Injection}

Water vapour is characterised by a significantly higher specific heat capacity than dry air, as shown in Figure 2. According to the equation of heat release during constant volume (Eq. (1)):

$$
\dot{\mathrm{Q}}=\dot{\mathrm{m}} \cdot \mathrm{c}_{\mathrm{V}} \cdot\left(\mathrm{T}_{3}-\mathrm{T}_{2}\right)=\dot{\mathrm{m}} \cdot \mathrm{c}_{\mathrm{V}} \cdot \Delta T
$$

where $\dot{\mathrm{Q}} \approx$ const, $\dot{\mathrm{m}} \approx$ const, $\mathrm{c}_{\mathrm{V}} \uparrow \Rightarrow \Delta \mathrm{T} \downarrow$

$\dot{\mathrm{Q}}$ is the heat release in $\mathrm{J} / \mathrm{s}$

$\dot{\mathrm{m}}$ is the mass of in-cylinder charge in $\mathrm{kg} / \mathrm{s}$

$\mathrm{c}_{\mathrm{v}}$ is the specific heat capacity in $\mathrm{J} /(\mathrm{kg} \cdot \mathrm{K})$

$\Delta \mathrm{T}$ is the increase in temperature due to combustion

$\mathrm{T}_{2}$ is the temperature at the end of compression in $\mathrm{K}$

$\mathrm{T}_{3}$ is the maximum combustion temperature in $\mathrm{K}$

Adding water to the in-cylinder charge involves an increase in specific heat capacity. Because of that, the increment of temperature due to combustion is lower. By liquid water injection in the intake manifold (or in the cylinder for direct injection), an additional cooling effect occurs by the evaporation process of the water. The heat for evaporating water is taken from the intake air and, consequently, the charge air temperature decreases, as can be seen in Eq. (2). A lower air charge temperature leads to a lower combustion temperature.

$$
\dot{\mathrm{m}}_{\mathrm{w}} \cdot \Delta h_{e v}=\dot{\mathrm{m}}_{\text {charge }} \cdot \mathrm{c}_{\mathrm{P}} \cdot \Delta \mathrm{T}_{\text {charge }}
$$

where $\dot{\mathrm{m}}_{\mathrm{w}}$ is the mass of injected water in $\mathrm{kg} / \mathrm{s}$

$\Delta \mathrm{h}_{\mathrm{ev}}$ is the enthalpy of evaporation in $\mathrm{J} / \mathrm{kg}$

$\dot{\mathrm{m}}_{\text {charge }}$ is the mass of intake air in $\mathrm{kg} / \mathrm{s}$ 
$\mathrm{c}_{\mathrm{p}}$ is the specific heat capacity in $\mathrm{J} /(\mathrm{kg} \cdot \mathrm{K})$

$\Delta \mathrm{T}_{\text {charge }}$ is the reduction of charge air temperature in $\mathrm{K}$.

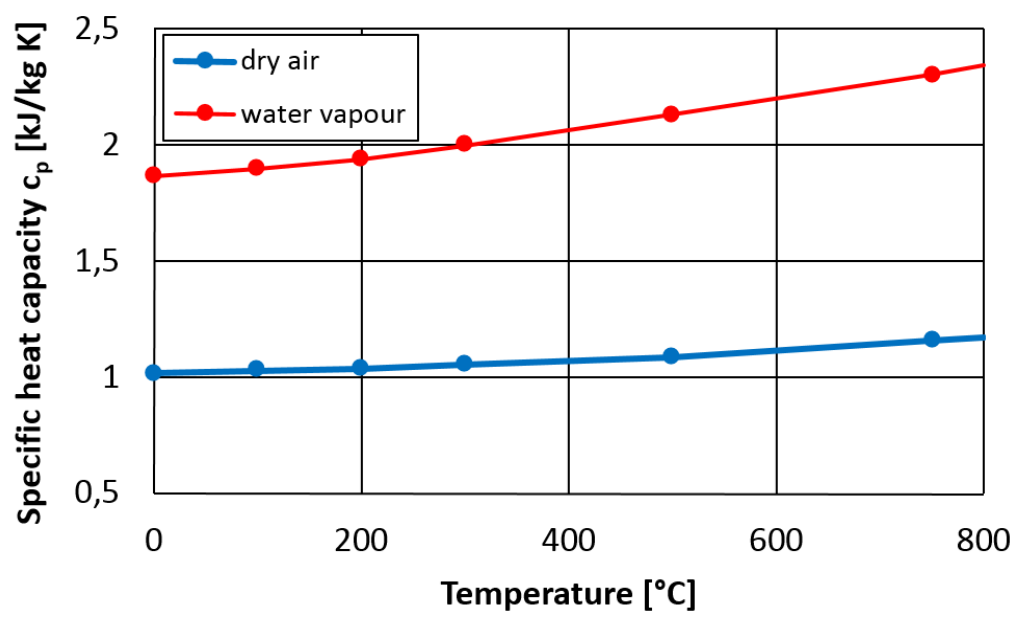

Figure 2. Specific heat capacity versus temperature for water vapour and dry air [18].

A high combustion temperature favours the formation of nitrogen oxides during combustion. Therefore, the reduction of combustion temperature by water injection leads to lower generation and emission of $\mathrm{NO}_{\mathrm{x}}$, as can be seen in Figure 3. Both strategies use a water-to-fuel ratio of $40 \%$ at $\mathrm{BMEP}=2.3$ bar. Compared to the intake manifold injection, a higher reduction by emulsion fuel was achieved, because the entire amount of water evaporates in the cylinder.

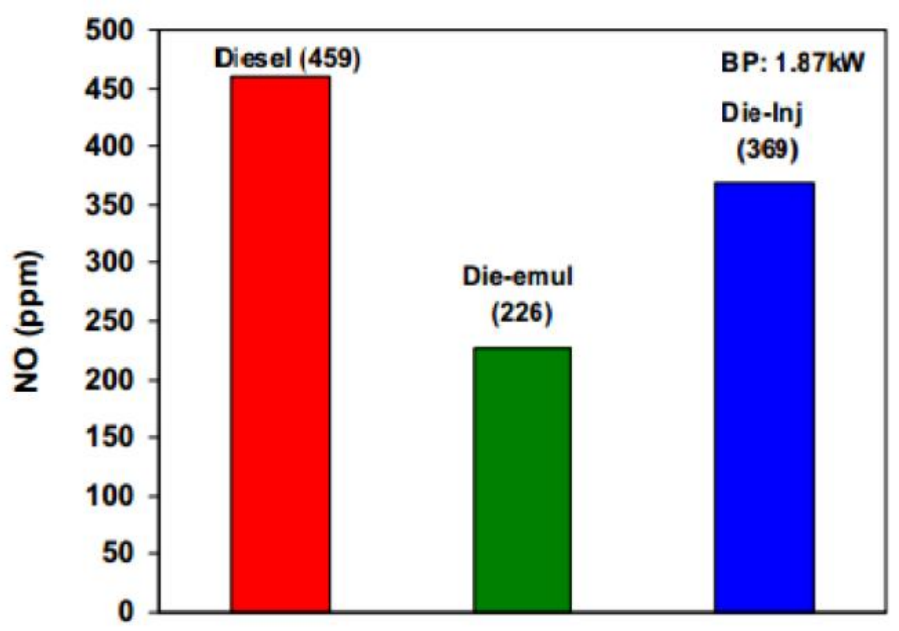

Figure 3. Comparison of $\mathrm{NO}_{\mathrm{x}}$-emission with diesel, diesel-water-emulsion (Dieemul) and intake manifold water injection (Die-Inj) [16].

\section{Thermodynamic Process of the Air Mass Flow}

The challenge when using intake manifold water injection is to achieve the absorption of the water by the air mass flow. Due to the arrangement of the water injection near the engine, it is possible to inject the water in "pre-heated" air, which provides a considerably higher water absorbing capacity than ambient air. Furthermore, a near- engine position 
shows benefits under dynamic engine operation. The objective is to keep the maximum water injection rate below the absorbing capacity limit of the air mass flow. In Figure 4, the thermodynamic process of moistening the air mass flow along the intake system is illustrated by using the Mollier diagram. Considering that experiments were carried out at a part-load operation with low supercharging pressure, a Mollier diagram for 1 bar pressure can be used with little error. Starting from tropical intake ambient conditions at $32^{\circ} \mathrm{C}$ temperature and $70 \%$ relative humidity (RH) (point 1 in Figure 4), the temperature of the air will be raised through the air path to a value of, for example, $100^{\circ} \mathrm{C}$ after the intercooler. The relative humidity is reduced to $3 \%$ (point 2). During this heating process, mainly caused by the hot surfaces in the intake system, the total amount of water contained in the air remains constant. With the theoretical process of an ideal adiabatic humidification, the air water content can be increased to saturation point (100\% HR) from 20 to 46 (g water)/ ( $\mathrm{kg}$ air) (point 3). At this point, a minimum intake temperature of $39^{\circ} \mathrm{C}$ is achieved theoretically. With a more realistic, non-adiabatic humidification, achieving the same water content of 46 (g water) / (kg air) (point 4), a temperature decrease from $100^{\circ} \mathrm{C}$ to $80^{\circ} \mathrm{C}$ and $13 \% \mathrm{RH}$ is achieved, but is still located far from the saturation point. Therefore, the higher the temperature of the air mass flow, the greater the amount of injected water that can be absorbed. This high water absorption capacity of air at high temperatures can be taken as an advantage of the near-engine intake manifold water injection strategy.

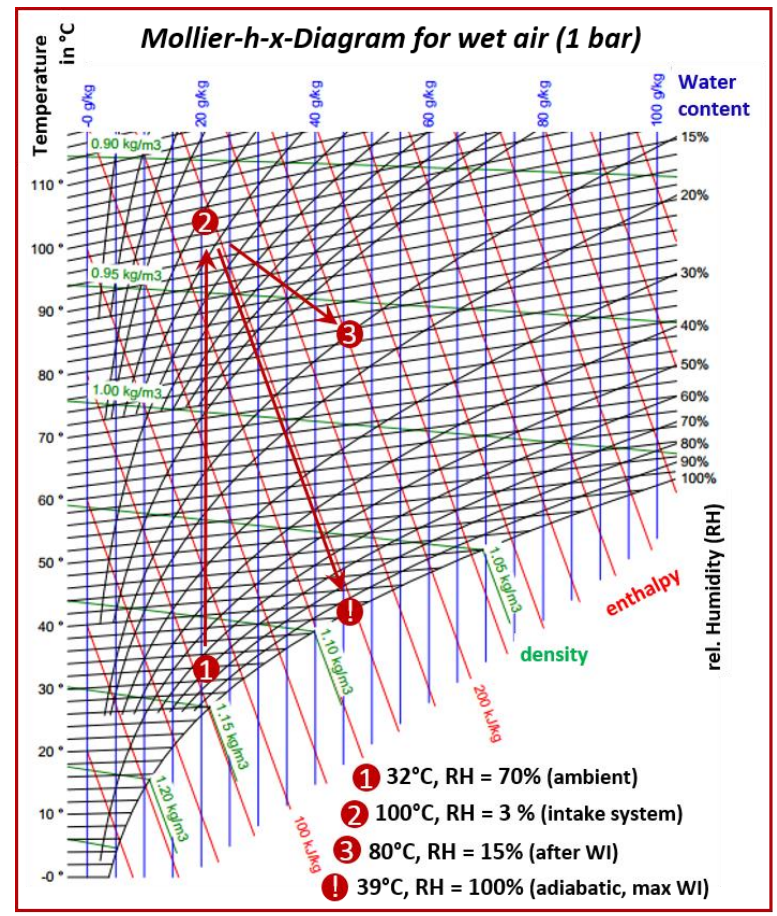

Figure 4. Example of the thermodynamic process of the air mass flow along the intake system. 


\section{EXPERIMENTAL SETUP}

\section{Test Bed Engine}

A modern series production 3-litre water-cooled DOHC diesel engine was used for the experiments, as shown in Figure 5. It is equipped with exhaust gas recirculation (EGR), a common rail injection system, turbocharger, intercooler and swirl flaps in the intake manifold. The crank case ventilation was modified to an external system to prevent deposit build-up in the intake system. Engine specifications are given in Table 1. For better understanding of the effects caused by water injection, the engine was equipped with numerous temperature sensors along the intake and exhaust system, as shown in Figure 6.

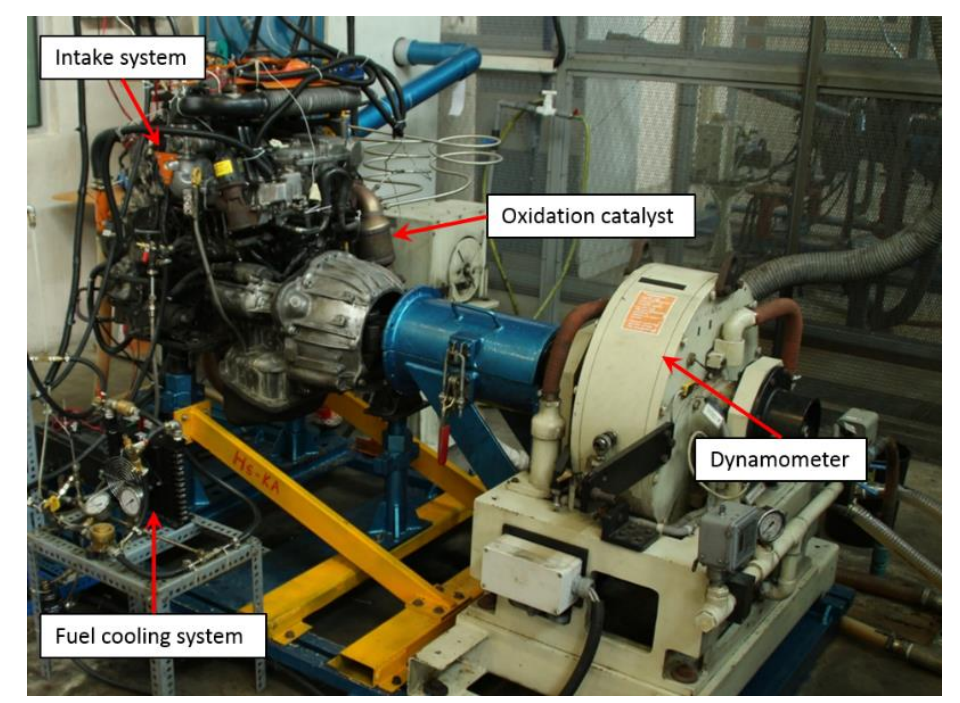

Figure 5. Test bed engine used for the test with water injection.

Table 1. Engine specifications.

\begin{tabular}{ll}
\hline Manufacturer & Isuzu \\
Engine code & 4JJ1E4C-L \\
Maximum power & $103 \mathrm{~kW} / 3600 \mathrm{rpm}$ \\
Maximum torque & $294 \mathrm{Nm} / 1,400-3400 \mathrm{rpm}$ \\
Bore x stroke & $94.4 \times 104.9 \mathrm{~mm}$ \\
Displacement & $3.0 \mathrm{litre}$ \\
Compression ratio & $17.5: 1$ \\
Combustion chamber type & Direct injection \\
Fuel system & Common rail system \\
Valve layout & Double overhead camshaft \\
Emission regulation & EPA Tier-3 / EC Stage IIIA \\
\hline
\end{tabular}

Figure 7 shows the applied water injection system schematically. For the test bed investigations, pressurised air was used to put the water tank under the required injection pressure. The electromagnetic valve was operated by a custom-made engine control unit (ECU) based on an Arduino processor, which was connected to a crank sensor. The 
required water injection duration and timing were provided to the controller manually via the user interface.

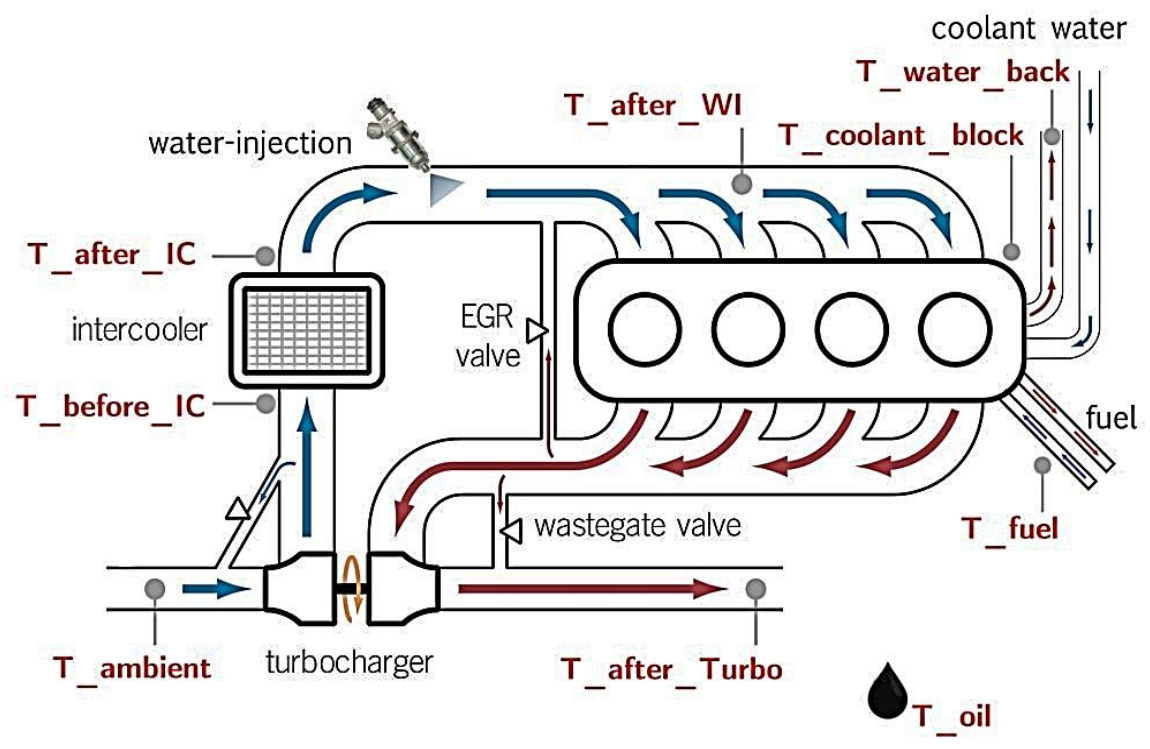

Figure 6. Temperature measurements at the test bed engine.

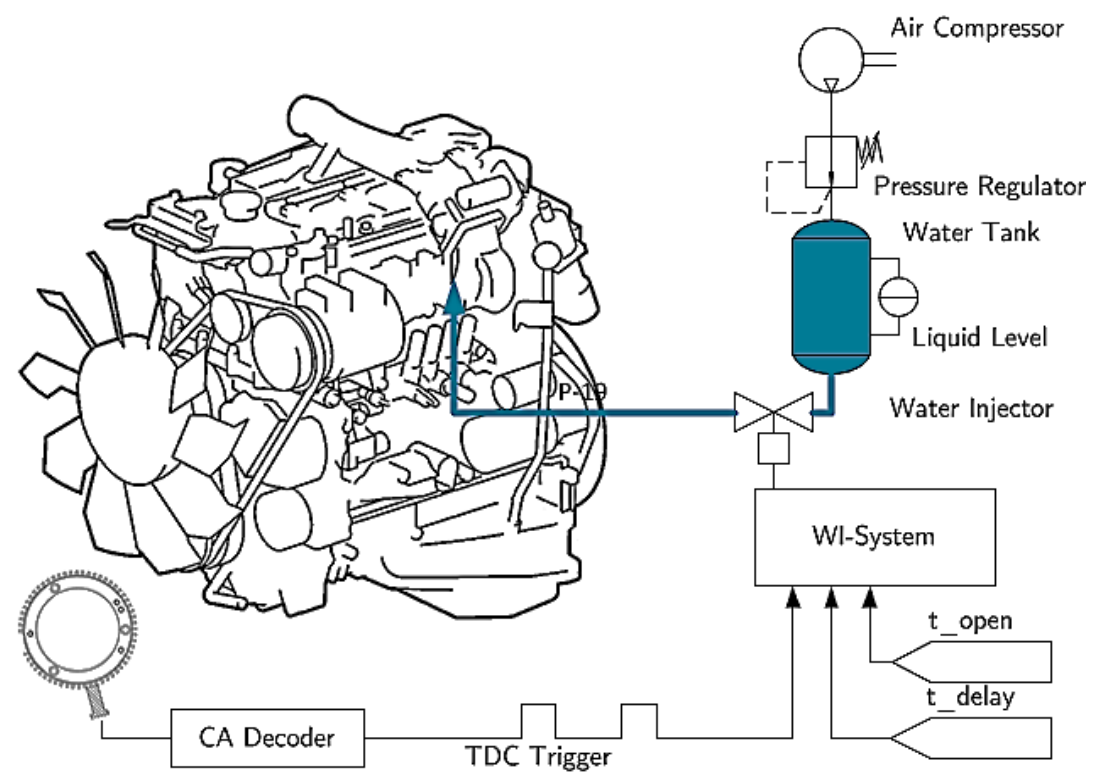

Figure 7. Water injection system (schematic) on the test bed engine.

Pre-investigation by optical measurement with gasoline multi-point injection injectors (MPI) showed that these injectors are characterised by a small spray angle of about $30^{\circ}$ and a large penetration length, which could lead to wall wetting in the intake system. A good atomization is necessary for sufficient mixing with the intake air and for low wall wetting effects in the intake pipe. A Denso E7T05072 gasoline direct injection injector was used, which was originally operated in Mitsubishi's first-generation GDI engines, showing a wide spray pattern when operated with water. This is a single-hole, 
swirl-type injector, which shows high atomization quality, even with low water injection pressures. Furthermore, these injectors are known for their high robustness regarding deposit build-up. Table 2 shows the specifications of the two injectors for original use with gasoline.

Table 2. Specifications of the multi-point injection (MPI) and gasoline direct injection (GDI) injectors.

\begin{tabular}{lcc}
\hline & $\begin{array}{c}\text { Denso } \\
\text { INP-064 } \\
\text { Mitsubishi MPI }\end{array}$ & $\begin{array}{c}\text { Denso } \\
\text { E7T05072 } \\
\text { Mitsubishi GDI }\end{array}$ \\
\cline { 2 - 3 } Approx. working pressure & $<5 \mathrm{bar}$ & $100-200 \mathrm{bar}$ \\
Flow rate at 5 bar & $240 \mathrm{~g} / \mathrm{min}$ & $540 \mathrm{~g} / \mathrm{min}$ \\
Number of holes & 2 & 1 \\
Spray angle overall & $30^{\circ}$ & $\approx 58^{\circ}$ \\
Power supply & $12 \mathrm{~V}$ & $12 \mathrm{~V}$ \\
Pick-up current & $3 \mathrm{~A}$ & $\approx 8 \mathrm{~A}$ \\
Hold current & $0.75 \mathrm{~A}$ & $>1 \mathrm{~A}$ \\
Coil resistance & $15 \Omega$ & $1.2 \Omega$ \\
\hline
\end{tabular}

Figure 8 illustrates the spray propagation images for the MPI injector and the GDI injector. The initial spray cone angle is respectively $30^{\circ}$ and $58^{\circ}$, but the spray for the MPI injector becomes more focused as it moves away from the injector tip. The injected water will be efficiently mixed with the air by penetrating a large volume for the GDI injector. This wide spray angle is caused by a swirl effect inside the direct injector tip, where the fluid has to pass a swirl chamber [19]. A water-cooled cylinder pressure sensor, Kistler type 6041A, was used to measure the in-cylinder pressure. This sensor was installed in the glow plug access in cylinder 1 and has a pressure range up to 250 bar, a sensitivity of $-20 \mathrm{pC} / \mathrm{bar}$, a maximum linearity of $\pm 0.5 \%$ FSO (full scale output) and a maximum hysteresis of $\pm 0.5 \%$ FSO.

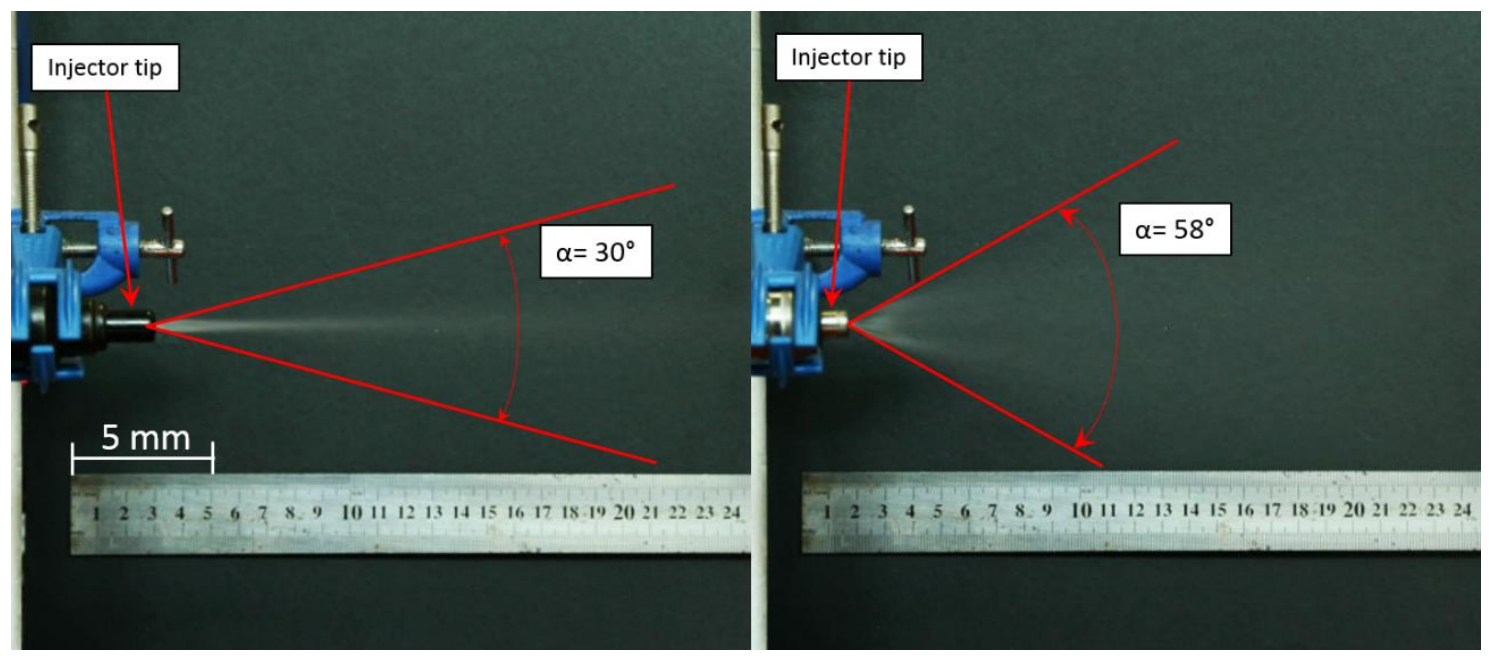

Figure 8. Injector and water spray propagation at injection pressure of 3 bar. 
A crank angle encoder (Kistler type 2613B) was used. It has a minimal signal resolution of $0.1{ }^{\circ} \mathrm{CA}$, a dynamic accuracy of $0.02{ }^{\circ} \mathrm{CA}$ at $10,000 \mathrm{rpm}$, a minimal resolution of the TTL trigger signal of $0.1^{\circ} \mathrm{CA}$ and a maximum operating speed of 20,000 rpm. Exhaust emission concentrations for $\mathrm{CO}, \mathrm{CO}_{2}, \mathrm{O}_{2}, \mathrm{NO}$ and $\mathrm{NO}_{\mathrm{x}}$ were measured by a portable gas analyser type KaneAuto 4-3. The accuracy of the measurement of the detected gases is $5 \%$. For $\mathrm{NO}_{\mathrm{x}}$ measurement, it has a measurement range up to $5000 \mathrm{ppm}$ and a resolution of $1 \mathrm{ppm}$. The in-cylinder pressure signal was recorded and analysed online regarding combustion parameters with a Dewetron DEWE-5000 combustion analyser. Particle mass was analysed using the gravimetric Particulate Matter Measurement method. By means of a vacuum pump, a sample of exhaust gas passes through a composite filter. After taking the sample, it is introduced into an oven for drying. When the water has evaporated from the sample, it has no influence on the measurement. The trapped mass of particles in this filter plate is proportional to the particulate emission of the engine. This mass is determined in a gravimetric measurement using an electronic scale.

The water injector is controlled by a pulse signal. This pulse is used as the input signal of an injector driver controller. When this driver receives this pulse signal, it supplies an electronic current through the solenoid of the injector and the needle of the injector opens. Therefore, by means of this pulse signal, the injector can be activated. It must be considered that there is a delay in opening and closing the injector relative to the pulse signal, mainly caused by the inertia of the needle. Besides, for small amounts of water, the duration of the pulse signal is very short and the needle will not fully open the injector. As a result, the water mass flow at very short opening duration shows high cyclic fluctuation due to different needle lifts between each cycle. This characteristic is known as ballistic behaviour of the needle travel. For engine operation with water injection, providing the exact amount of injected water that is required at each operating point of the engine is essential. Therefore, an accurate calculation of the water mass per injection depending on the duration of the pulse is needed. To determine the range in which the injector operates under ballistic behaviour, tests with variable injector opening times were executed. The injector was activated for 10 seconds by a pulse-width modulation (PWM) signal with a constant frequency of $50 \mathrm{~Hz}$. The water was injected into a vessel to weigh the mass. Given that the pulse is directly associated with the activation time of the injector, a correlation between the water mass per injection cycle and activation time (duration of current feed to the solenoid-controlled injector) can be obtained, as shown in Figure 9. The figure shows that this injector is characterised by significant ballistic behaviour for an injector activation time up to $0.7 \mathrm{~ms}$. Above this value, a linear correlation was found. The injector curve was analysed for different injection pressures. The results shown in Figure 9 were obtained for a constant injection pressure of 5 bar.

Equation (3) shows the method to determine the dependence between the injected water mass and the activation time of the injector.

$$
\begin{aligned}
& \mathrm{m}_{\mathrm{w}}=\frac{\Delta \mathrm{y}}{\Delta \mathrm{x}} \cdot t_{\text {activ }}+y_{\text {value }} \\
& \mathrm{m}_{\mathrm{w}}=3.45 \cdot t_{\text {activ }}-0.85 \\
& t_{\text {activ }}=\frac{\mathrm{m}_{\mathrm{w}}+0.85}{3.45}
\end{aligned}
$$


where $m_{w}$ is the water mass per injection event in $\mathrm{mg}$

$\mathrm{t}_{\text {open }}$ is the injector activation time in $\mathrm{ms}$

$\Delta y / \Delta x$ is the gradient of the curve in $\mathrm{mg} / \mathrm{ms}$

$\mathrm{y}_{\text {value }}$ is the intersection of the curve with $\mathrm{y}$-axis in $\mathrm{mg}$.

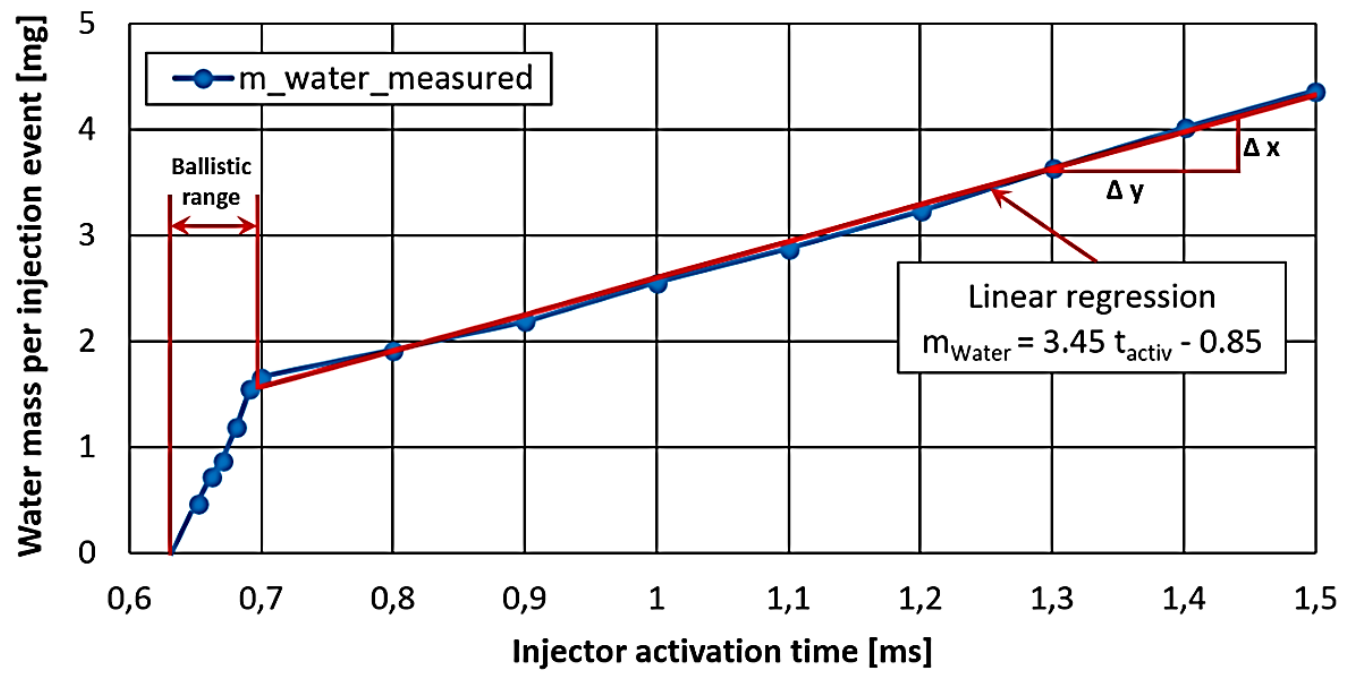

Figure 9. Injector characteristic curve.

In accordance with performance requirements, a microcontroller unit of the Arduino family (Uno R3) was used, shown in Figure 10. Custom-made software was developed to run the system.

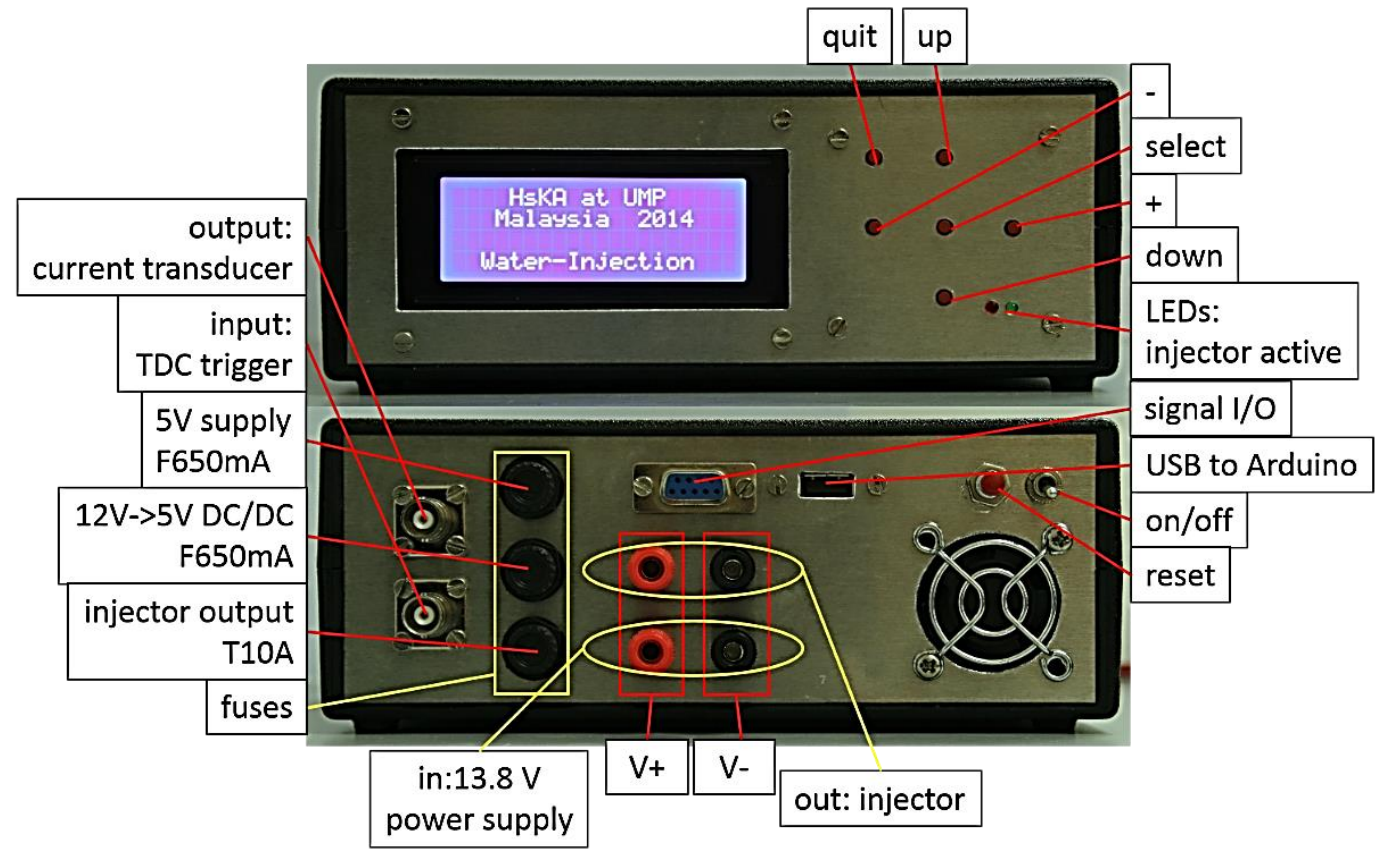

Figure 10: Electric control unit based on Arduino. 
To find the injector position for the best mixing of the water with the intake air, different locations for the injector were investigated. The installation space is limited around the intake manifold. Figure 11 shows a schematic arrangement of the three positions of the injection regarding the air mass flow direction.

- Position 1: Upper position, unidirectional to the intake air flow

- Position 2: Sideways to the air flow

- Position 3: Reverse to the air flow on the bottom of the intake manifold

- A temperature sensor was installed in the intake manifold close to the intake valve of cylinder 4 . This allowed analysis of the temperature drop of the intake air caused by water injection.
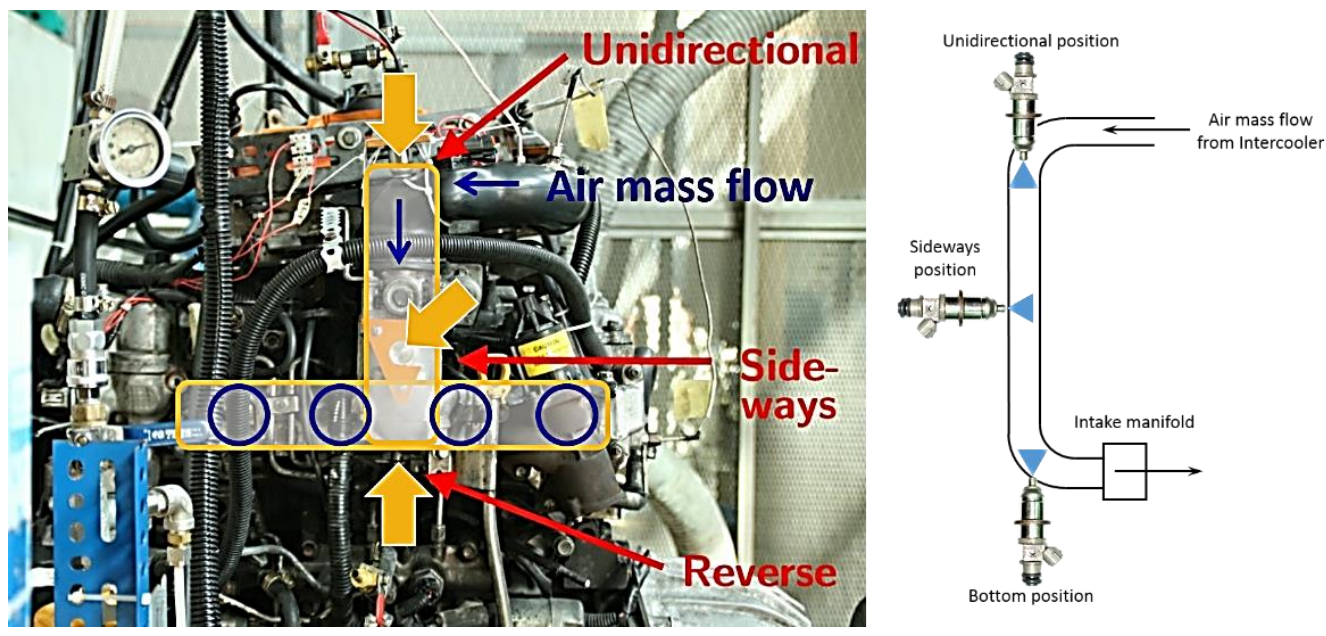

Figure 11. Schematic arrangement of the three positions of the water injector regarding the air mass flow direction in a frontal view (left) and a side view (right).

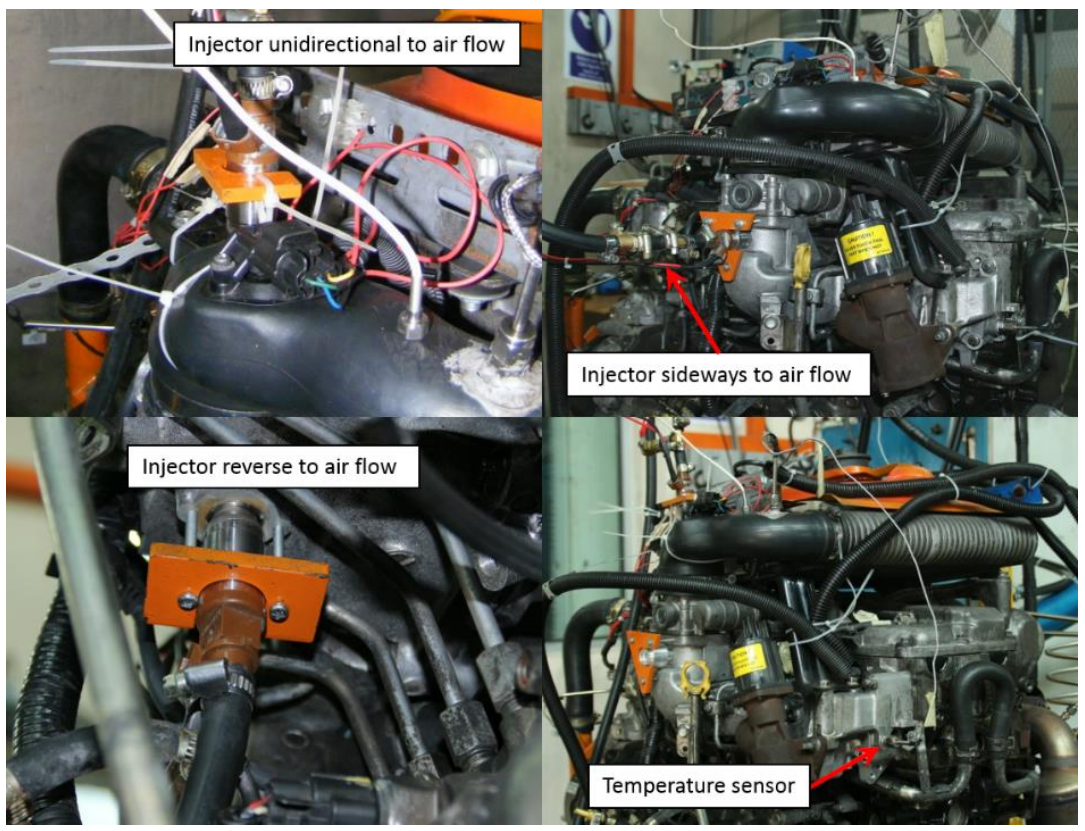

Figure 12. Positions of the injector and location of the temperature sensor near to the intake valves of cylinder 4 . 
Figure 12 shows the installation of the injector for the three positions. To achieve a robust mounting, the locations were prepared to install the injector with a gasket and a retaining ring.

\section{RESULTS AND DISCUSSION}

In a first step, the investigations with water injection were carried out for selected partload operation with a brake mean effective pressure BMEP $=2,3.5$ and 5 bar and an engine speed of $n=2000 \mathrm{rpm}$. The amount of the injected water was quantified by the water-to-fuel ratio $\Omega$.

\section{Intake Temperature}

The experiment with 5 bar BMEP is shown in Figure 13. The temperatures of the intake air downstream of the water injection (measured close to the inlet valve) and the exhaust temperature are displayed over the water-to-fuel ratio. The exhaust temperature decreases from $402{ }^{\circ} \mathrm{C}$ to $383{ }^{\circ} \mathrm{C}$. The intake temperature downstream of the water injector position drops from $115.2{ }^{\circ} \mathrm{C}$ to $95.5^{\circ} \mathrm{C}$. The other temperatures (cooling water, oil, ambient air, fuel) remained constant during the whole test run. The decrement of the temperature downstream of the water injection and the exhaust temperature for $\mathrm{BMEP}=2,3.5$ and 5 bar are shown in Table 3.

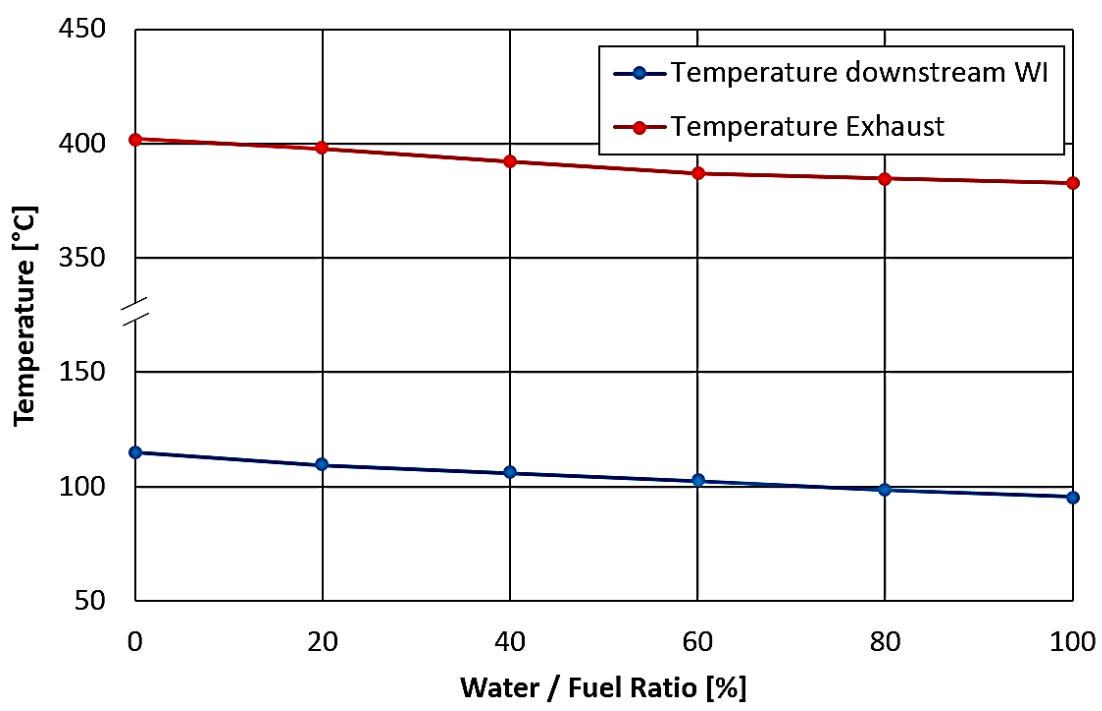

Figure 13. Influence of water injection on intake air temperature at $\mathrm{BMEP}=5$ bar.

According to Eq. (2), the greater the injected water mass, the greater the amount of heat taken from the intake air due to evaporation of the water and the lower the resulting temperature of the air mass flow. As a consequence, for the maximum water-to-fuel ratio $(100 \%)$, the maximum decrement of intake air temperature is achieved, as seen in Figure 14. On the other hand, according to Eq. (1) and Figure 2, the greater the injected water mass, the higher the specific heat capacity of the air-water mixture that enters the cylinder and the lower the combustion temperature and the exhaust temperature. As a consequence, at the maximum water-to-fuel ratio $(100 \%)$, the maximum decrement of exhaust temperature is achieved. Figure 14 shows the dynamic behaviour of the intake 
temperature after activation of water injection. The temperature was measured close to the intake valve. The sideways injector position showed the best response behaviour.

Table 3. Temperature decrement downstream of water injector and in exhaust.

\begin{tabular}{lcccccc}
\hline BMEP & \multicolumn{2}{c}{$\begin{array}{c}\text { Temperature downstream } \\
\text { of water injection }\end{array}$} & \multicolumn{2}{c}{ Exhaust temperature } \\
\hline & \multicolumn{2}{c}{$\mathrm{T}\left[{ }^{\circ} \mathrm{C}\right]$} & $\Delta \mathrm{T}[\mathrm{K}]$ & \multicolumn{2}{c}{$\left[{ }^{\circ} \mathrm{C}\right]$} & $\Delta \mathrm{T}[\mathrm{K}]$ \\
\cline { 2 - 7 } & $\Omega=0$ & $\Omega=1$ & & $\Omega=0$ & $\Omega=1$ & \\
\hline 3 bar & 85.8 & 70.8 & 15 & 226 & 210 & 16 \\
5 bar & 109 & 94.8 & 14.2 & 323 & 309.6 & 13.4 \\
\hline
\end{tabular}

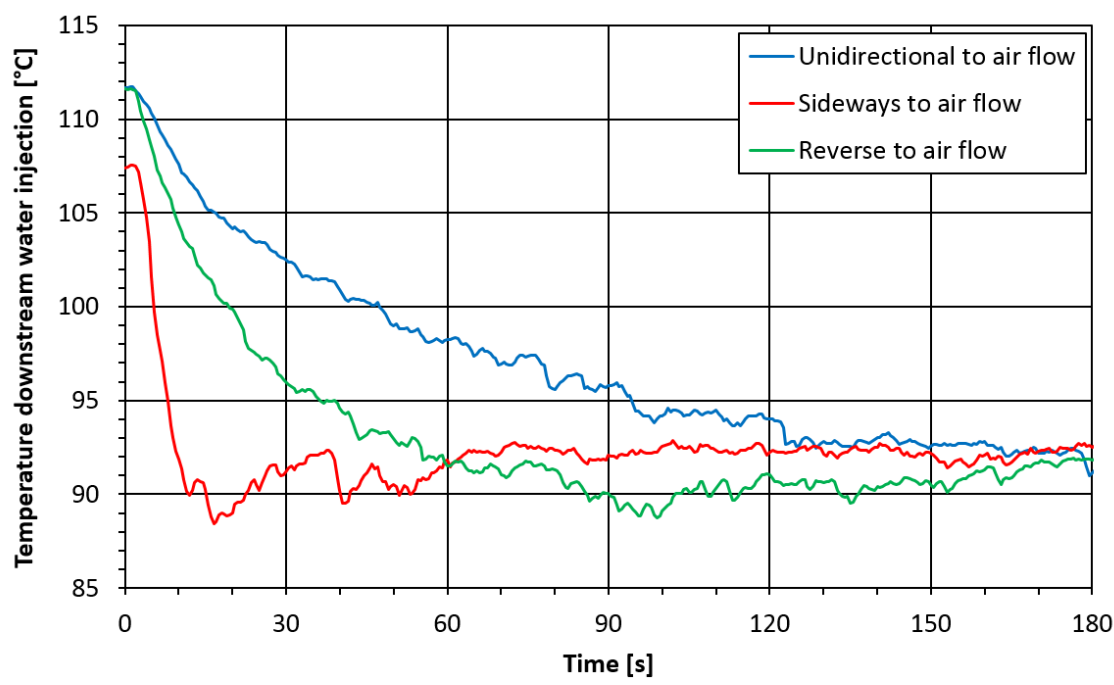

Figure 14. Dynamic behaviour of intake temperature after activation of water injection with different injection positions for $\mathrm{BMEP}=5 \mathrm{bar}$ and $\mathrm{W} / \mathrm{F}=100 \%$.

For a good mixture of water and air, the orientation of the injection with respect to air flow gains importance. An orientation that favours the taking of the water by the air flow will provide a better mixture of both components. For the evaporation of the water, the proximity of the injector to the intake valve is important. The closer the injector location is to the intake valve, the faster the evaporation of the water will be, due to the higher intake air temperature. As shown in Figure 11, the unidirectional position is quite far from the intake valve and therefore it has the worst response behaviour. The reverse position has the advantage that it is in the nearest position to the intake valve, but its orientation with respect to the air flow is less favourable for good mixing. Although the sideways position lies a little far away from the intake valve, the right-angle orientation of the injection enables it to achieve a good compromise between evaporation and mixing, providing the best response behaviour.

Important aspects for a good dynamic behaviour of the water injection are a proper mixture and homogenisation and fast evaporation of the water. This can be achieved with a suitable orientation of the injector, a design of injector that provides a good fine atomisation of the water, and a design of the intake system geometry that guides the air 
mass flow and favours a sufficient mixing of water and air. The implementation of these measures is linked to an increment of the costs of the system. A compromise between excellent air water mixture and increasing costs must be achieved. In Figure 15 the $\mathrm{NO}_{\mathrm{x}}-$ PM trade-off for 2, 3.5 and 5 bar BMEP is shown for different water injection rates $(0 \%$; $20 \% ; \ldots 100 \%)$. At very low load conditions, $\mathrm{NO}_{\mathrm{x}}$ emissions can be decreased by adding water without drawback in soot emissions. In the experiment with 2 bar BMEP, the PM emissions do not change significantly. Furthermore, soot emissions are very low due to the high air-fuel ratio [20]. In the experiment with 3.5 bar BMEP, the PM emissions increase slightly with increasing water mass ( $2.35 \mathrm{mg}$ to $3.5 \mathrm{mg}$ ), while $\mathrm{NO}_{\mathrm{x}}$ emissions are decreased significantly. In the experiments with 5 bar BMEP, the PM emissions increase as well, from $4.3 \mathrm{mg}$ to $6 \mathrm{mg}$, with the increasing amount of water. As long as the water-to-fuel ratio is less than $40 \%, \mathrm{NO}_{\mathrm{x}}$ emissions can be lowered without drawback in PM emissions.

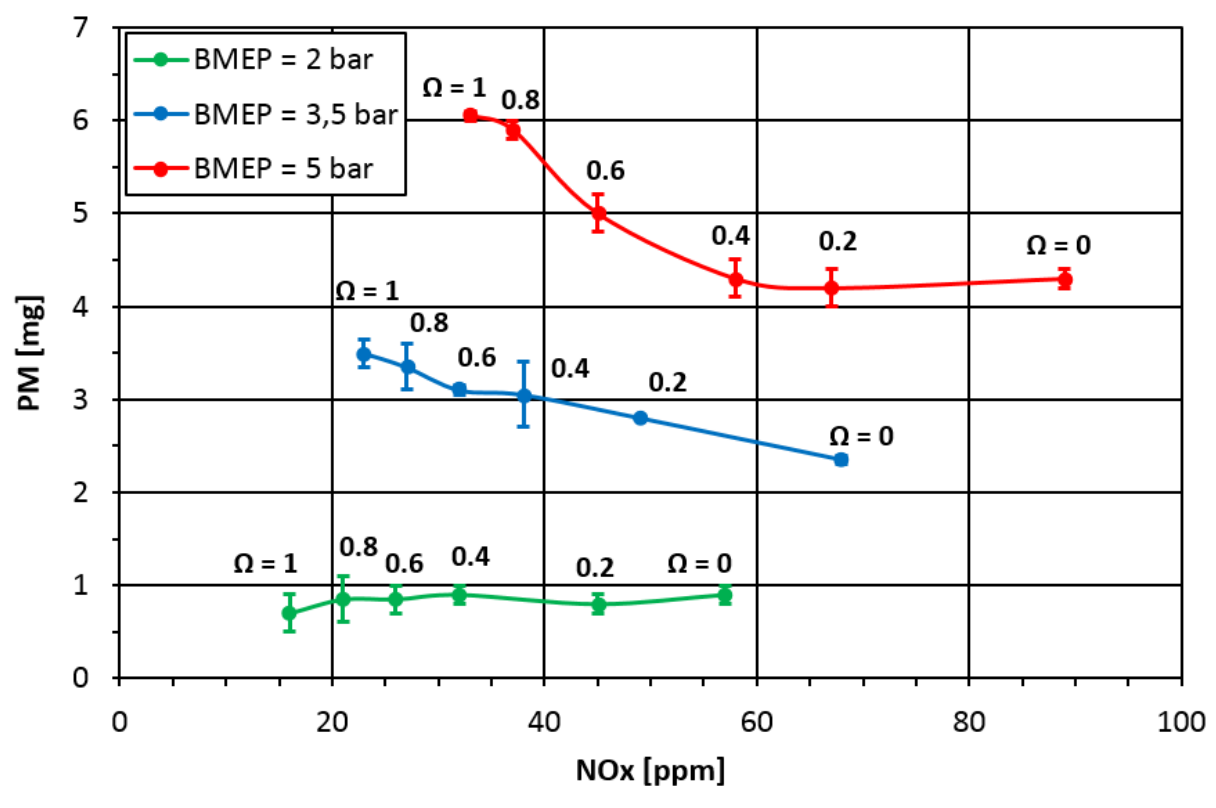

Figure 15. PM- $\mathrm{NO}_{\mathrm{x}}$ trade-off for different masses of water injection and for different BMEP.

The results obtained can be compared with other research work on water injection systems applied to diesel engines. Figure 16 shows a comparison with the work of Samec et al. [11], Kegl et al. [12] and Subramanian [16], for different water-to-fuel ratios. Results for intake manifold water injection (IM) and water-fuel emulsion (WFE) are represented. For the case of intake manifold water injection and a water-to-fuel ratio of $20 \%$, this work achieves a higher reduction of nitrogen oxides than the works of Samec et al. and Kegl et al. Compared to the work of Subramanian, for a water-to-fuel ratio of $40 \%$, the results of this work are better until a BMEP of approximately 5 bar. Above this value, Subramanian's work shows a higher reduction of nitrogen oxides. Compared to operation with water-fuel emulsion, the $\mathrm{NO}_{\mathrm{x}}$ reduction values obtained in this work by intake manifold water injection are higher than the values obtained by Samec et al. and similar to the values obtained by Kegl et al. Compared to the work of Subramanian, the $\mathrm{NO}_{\mathrm{x}}$ reduction is lower, but only for values of BMEP under approximately 3 bar. 


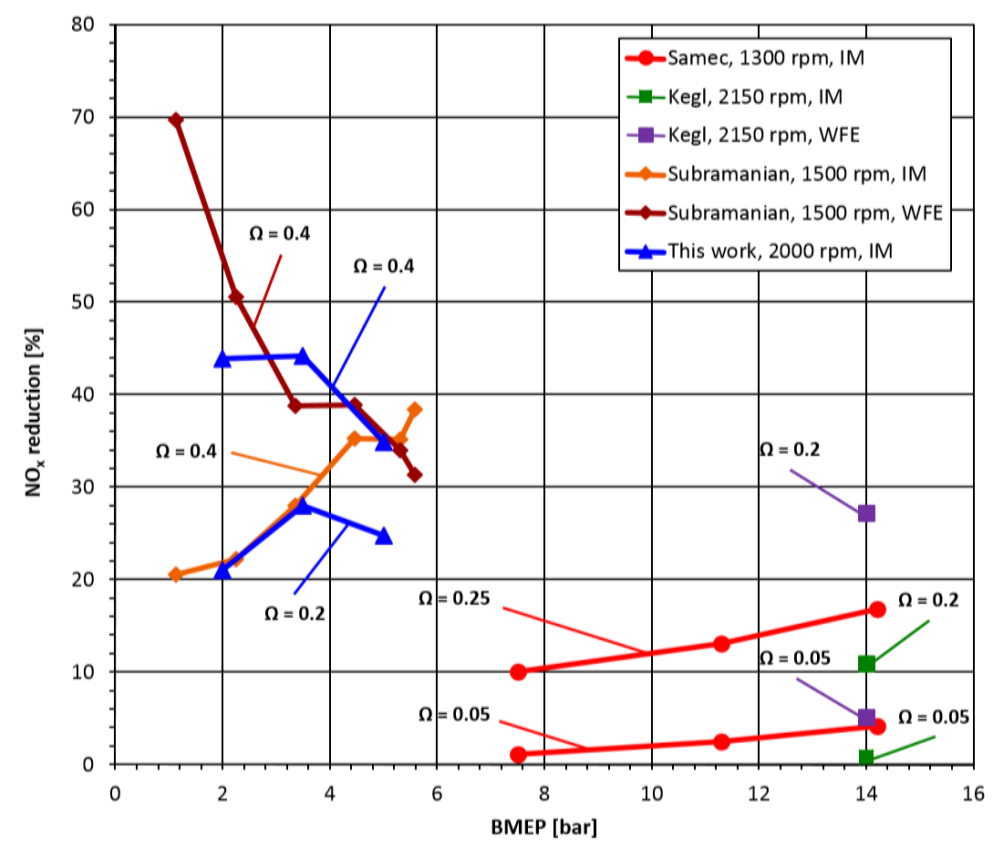

Figure 16. Comparison of the results obtained with other published results for intake manifold water injection (IM) and water-fuel emulsion (WFE) for different water-tofuel ratios $(\Omega)$.

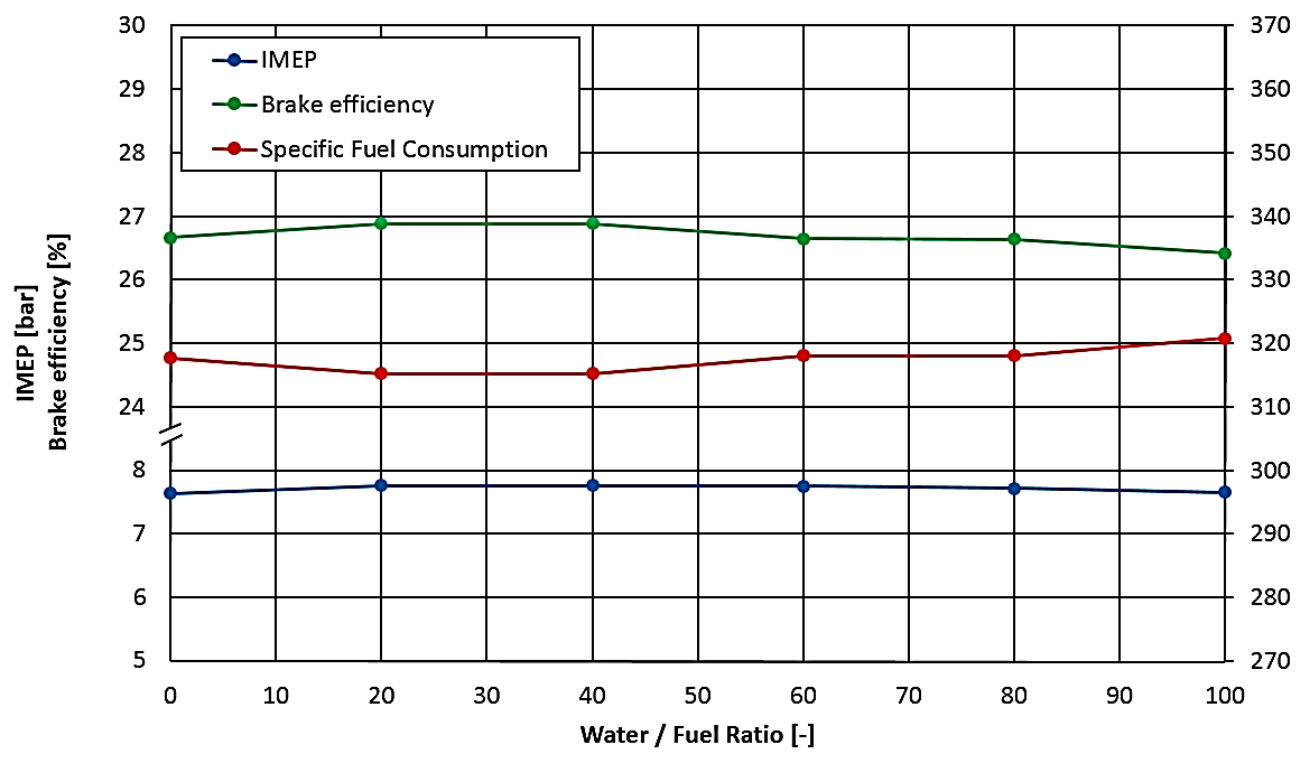

Figure 17. IMEP, brake efficiency and specific fuel consumption for different water-to-fuel ratios at $\mathrm{BMEP}=5$ bar.

Figure 17 shows the engine parameters IMEP, brake efficiency and specific fuel consumption for different water-to-fuel ratios at the 5 bar BMEP operation point. Only a small effect can be observed when the water-to-fuel ratio is varied until $\Omega=40 \%$. The effective specific fuel consumption BSFC is almost constant, with a value of about $318 \mathrm{~g} / \mathrm{kWh}$ correlating with brake efficiency of about $26.8 \%$. Also, the engine load is almost constant (IMEP $\approx 7.6$ bar) for all the investigated water injection rates. The 
combustion process was analysed by calculation of the heat release rates for water/fuel rates of $\Omega=0 \%, 40 \%$ and $100 \%$, as Figure 18 shows. At BMEP $=5$ bar, the effect of water injection on the main combustion is negligible. Slight differences can be seen during the pre-combustion of the pilot injection fuel. With an increasing amount of water, inflammation is delayed due to increasing ignition delay.

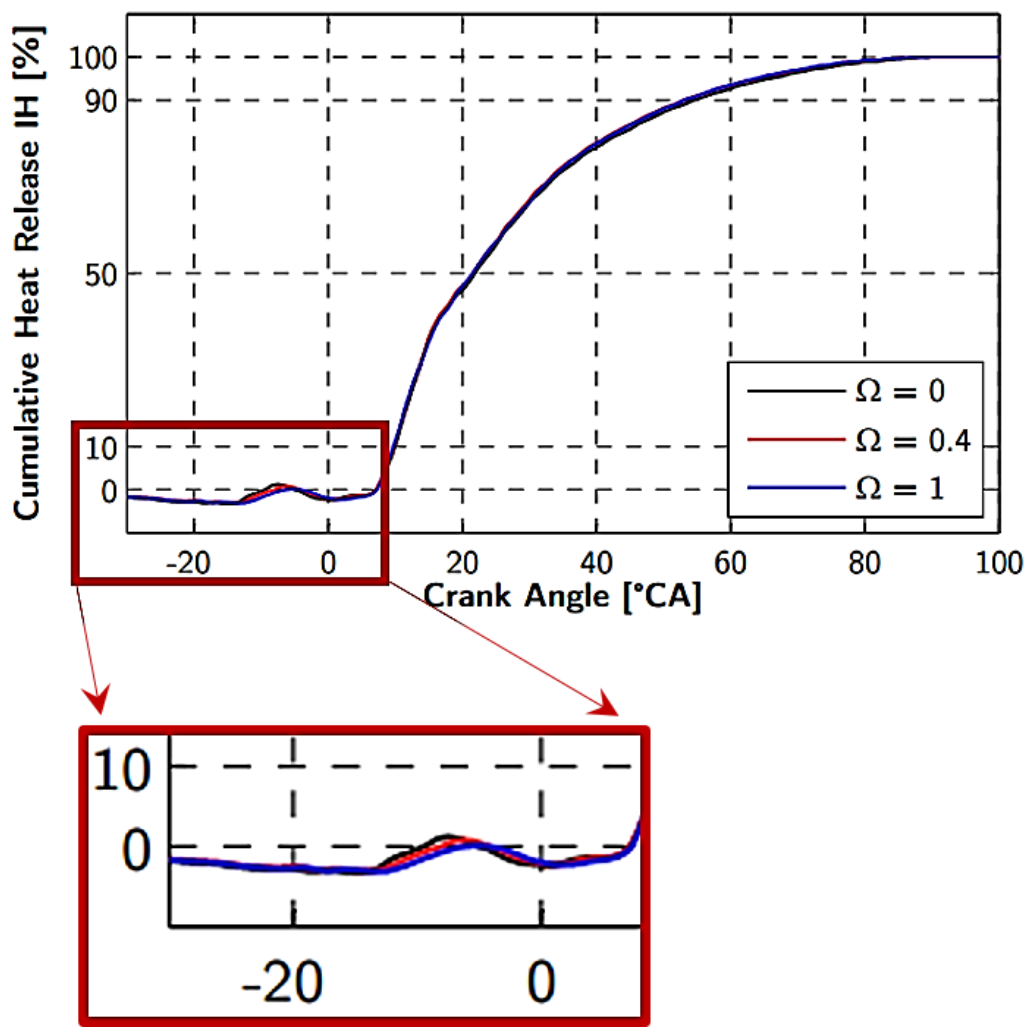

Figure 18. Cumulative heat release at $\mathrm{BMEP}=5$ bar.
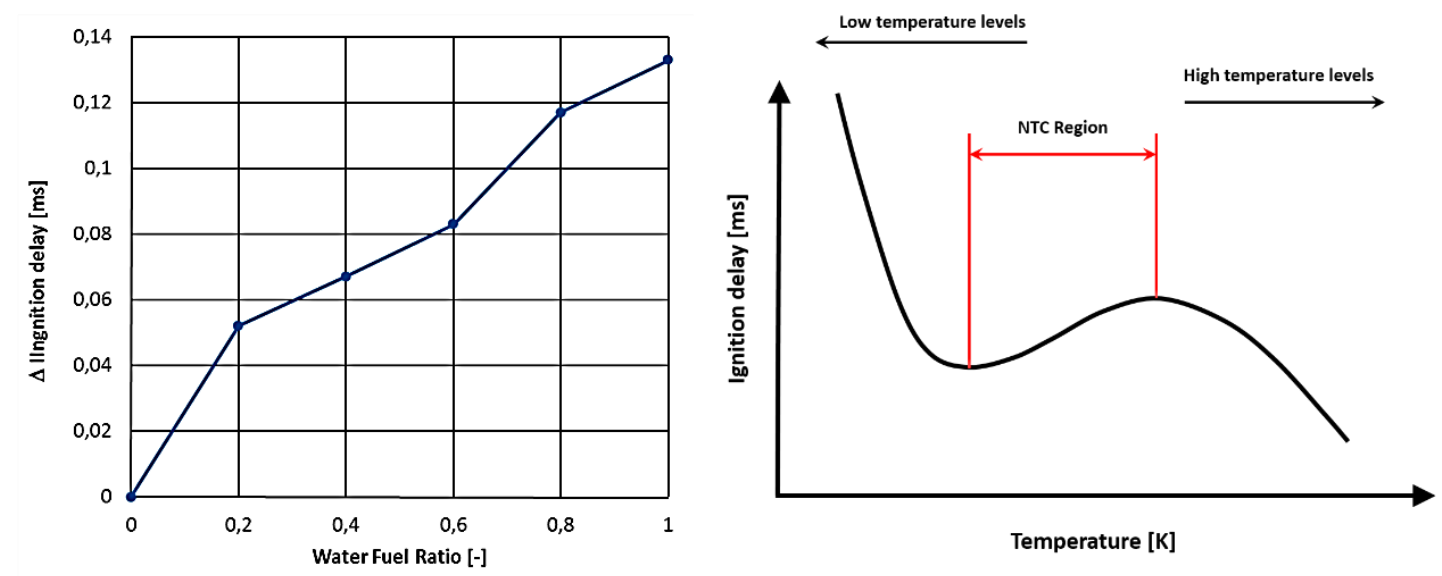

Figure 19. Ignition delay for different water-to-fuel ratios at $\mathrm{BMEP}=5$ bar (a); dependence of the ignition delay on the temperature (b). 
The effect on the ignition delay of the pre-combustion was analysed. It is shown in detail in Figure 19(a). In a diesel engine, the ignition delay is the time from the start of injection to the start of ignition. During this period, complex physical and chemical processes occur. The physical processes lead to the formation of an auto-ignitable mixture and include the atomization of the fuel, vaporization and mixing of fuel vapour with air. The chemical processes include highly complex chain-branching mechanisms and lead to auto-ignition of the hydrocarbons contained in the fuel. The dependence of ignition delay on the temperature is shown in Figure 19(b). A rise of the temperature decreases the ignition delay because a temperature increase causes chain-branching reactions. The exact temperature levels in this diagram are dependent on the pressure, because a pressure increase also favours chain-branching reactions. The region of intermediate temperature is characterised by the negative temperature coefficient (NTC), which represents an increase of ignition delay for increasing temperatures. This effect occurs due to reverse chain-branching reactions (degenerating chain-branching reaction) [21, 22]. According to Eq. (2), with an increment of injected water mass the temperature of the air that enters the cylinder is lower. Consequently, the temperature level of the in-cylinder charge air during compression is lower and the ignition delay of the fuel is slightly higher.

\section{CONCLUSIONS}

In this paper, a water injection system for a four-cylinder diesel engine is presented which uses a single injector located in the intake system of the engine. The system was developed and used for test bed investigation under part-load operation conditions. A significant reduction in $\mathrm{NO}_{\mathrm{x}}$ emissions was achieved, while particulate emissions were not affected at a very low engine load of BMEP $=2$ bar. With the presented system, the excellent results of operation with emulsion fuels in other publications could be almost achieved. This is due to a single but as close as possible to the inlet valve position of the water injector and a suitable orientation of the injection regarding the air mass flow, which provides a good mixing of the water with the air mass flow. At higher part-load operation (BMEP $=3.5$ bar and 5 bar) and water-fuel rates below $40 \%$, good results regarding $\mathrm{NO}_{\mathrm{x}}$ and particulate emissions were achieved. Even for high water injection rates of up to $100 \%$ water to fuel mass, the combustion characteristics showed a negligible effect on the main combustion and a slight increase in ignition delay of $0.13 \mathrm{~ms}$ at the combustion of the pilot-injected fuel. This work was carried out for a maximum part-load operation of BMEP $=5$ bar. Future research works should include the evaluation of the water injection system for higher load operation points as well as high engine speeds, with regard to the next emission legislation changes that will come into effect in 2017, bringing along Real Drive Emission (RDE) issues. On the other hand, other parameters such as, for example, the influence of the ambient air humidity on the operation of the engine could be tested. An intake air-conditioning unit would help to study the effect of different ambient conditions.

\section{ACKNOWLEDGEMENTS}

The authors would like to thank Universiti Malaysia Pahang for providing laboratory facilities. 


\section{REFERENCES}

[1] Schlücker E., W. E. Küttner. Kolbenmaschinen: Springer-Vieweg Verlag; 2009.

[2] Sass F. Geschichte des deutschen Verbrennungsmotorenbaus: von 1860 bis 1918: Springer; 1962.

[3] Prien J, Rodeike P. Messerschmitt Bf 109 F, G, K Series: An Illustrated Study2004.

[4] Renault. Renault pays homage to turbocharged heritage at Silverstone.

[5] Division) S-SASC. Manual for water injection. Nyköping, Sweden1988.

[6] Aquamist. A technical article on Prodrive's Subaru WRC car.

[7] Sport AMu. MTM-Audi A3 mit Wassereinspritzung. 2007.

[8] Israel U, Fischer S. Mit Wasser gegen die Rußemissionen. MTZ Motortechnische Zeitschrift. 2014;75.

[9] Release BP. BMW M introduces innovative technology for the 2015 Season.

[10] Riom E, Larsson L, Hagström U. Verminderung des NOx-Ausstoßes von Dieselmotoren. MTZ - Motortechnische Zeitschrift. 2002;63.

[11] Samec N, Dibble R, Chen J, Pagon A. Reduction of NOx and soot emission by water injection during combustion in a diesel engine. FISITA 2000 World Automotive Congress. Seoul, Korea2000.

[12] Kegl B, Pehan S. Reduction of diesel engine emissions by water injection. SAE Technical Paper. 2001.

[13] Odaka M, Koike N, Tsokamoto Y, Narusawa K, Yoshida K. Effects of EGR with a supplemental manifold water injection to control exhaust emissions from heavyduty diesel powered vehicles. SAE Technical Paper. 2001.

[14] Tauzia X, Maiboom A, Shah S. Experimental study of inlet manifold water injection on combustion and emissions of an automotive direct injection Diesel engine. Energy. 2010;35:3628-39.

[15] Takasaki K. Verbesserung der Verbrennung im Dieselmotor durch geschichtete Wassereinspritzung. MTZ - Motortechnische Zeitschrift. 1998;59.

[16] Subramanian K. A comparison of water-diesel emulsion and timed injection of water into the intake manifold of a diesel engine for simultaneous control of NO and smoke emissions. Energy Conversion and Management. 2011;52:849-57.

[17] Böhm M, Mährle W, Bartelt H, Rubbert S. Funktionale Integration einer wassereinspritzung in den ottomotor. MTZ - Motortechnische Zeitschrift. 2016;7.

[18] Pflugradt N. Mollier-hx-Diagramm für feuchte Luft2009.

[19] Kettner M. Experimentelle und numerische untersuchungen zur optimierung der entflammung von mageren gemischen bei ottomotoren mit direkteinspritzung. [Doctoral Thesis]: University of Karlsruhe (KIT); 2006.

[20] Mollenhauer K, Tschöke H. Handbuch dieselmotoren. 3rd ed: Springer; 2007.

[21] Baumgarten C. Mixture formation in internal combustion engines. 1st Ed: Springer; 2006.

[22] Merker G, Schwarz C, Teichmann R. Combustion engines development. mixture formation, combustion, emissions and simulation. 2nd ed: Springer; 2012. 